Original Article

\title{
MOLECULAR DOCKING STUDIES AND SYNTHESIS OF 3, 4 - DISUBSTITUTED TRIAZOLES AS MYCOBACTERIUM TUBERCULOSIS ENOYL-ACP REDUCTASE AND CYP-51 INHIBITORS
}

\author{
NEETHU DASAN, G. BABU, SHINY GEORGE* \\ Department of Pharmaceutical Chemistry, Devaki Amma Memorial College of Pharmacy, Malappuram, Kerala, India 673634 \\ Email: georgeshiny28@gmail.com
}

Received: 31 Aug 2018 Revised and Accepted: 28 Nov 2018

\begin{abstract}
Objective: To design, synthesize and in vitro antitubercular, antifungal and antioxidant evaluation of some novel mercapto 1, 2, 4-triazole derivatives.

Methods: New derivatives were designed by using various software like ACD Lab chemsketch, molinspiration and autodock. Designed molecules are obeying Lipinski's rule of five and having highest binding score was selected for the synthesis. The synthesized compounds were subjected to TLC, melting point determination, FTIR, ${ }^{1} \mathrm{H}$ NMR, ${ }^{13} \mathrm{C}$ NMR and mass spectral analysis. The newly synthesized compounds were investigated for in vitro antitubercular evaluation by MABA method, antifungal evaluation by cup plate method and antioxidant evaluation by DPPH scavenging assay

Results: A virtual screening was carried out through docking designed compounds into the InhA and CYP-51 binding site to predict if these compounds have an analogous binding mode of the enoyl ACP reductase (InhA) and CYP-51 inhibitors. Three derivatives (4a1, 4a2 and 4a3) were selected for the synthesis with the help of in silico modeling. The selected derivatives were synthesized by a conventional method. All the synthesized compounds showed a characteristic peak in FT IR, ${ }^{1} \mathrm{H}$ and ${ }^{13} \mathrm{C}$ NMR and mass spectroscopic studies. All the selected derivatives showed antitubercular, antifungal and antioxidant activity.
\end{abstract}

Conclusion: The derivatives were synthesized adopting simple and laboratory friendly reaction conditions to give the target compounds in quantitative yields. Newer derivatives possess good antitubercular, antifungal and antioxidant activity.

Keywords: Triazole, Docking, Antitubercular, Antifungal, Antioxidant

(c) 2019 The Authors. Published by Innovare Academic Sciences Pvt Ltd. This is an open access article under the CC BY license (http://creativecommons.org/licenses/by/4.0/) DOI: http://dx.doi.org/10.22159/ijpps.2019v11i1.29428

\section{INTRODUCTION}

In the past, most drugs have been discovered either by identifying the active ingredient from traditional remedies or by serendipitous discovery. A new approach has been identified to understand how disease and infections are controlled at the molecular and physiological level and to target specific entities based on this knowledge [1]. Molecular docking is a method, which predicts the preferred orientation of one molecule to a second when bound to each other to form a stable complex. Knowledge of the preferred orientation, in turn, may be used to predict the strength of association or binding affinity between two molecules using scoring functions which are used to predict the strength of the noncovalent interaction (also referred to as binding affinity) between two molecules after they have been docked [2]. Molecular docking has become an increasingly important tool for drug discovery.

Mycobacterium tuberculosis (M. tuberculosis) is the fundamental etiologic agent for human tuberculosis and is the biggest killer due to bacterial infection in the world today. Tuberculosis accounts for about $7 \%$ of all deaths in developing countries and $26 \%$ of avoidable adult deaths [3]. Due to the reduced effectiveness of current drugs resulting from the emergence of multidrug-resistant tuberculosis (MDR TB) and co-infection with human immunodeficiency virus (HIV), there is an urgent need to develop new natural or synthetic antitubercular drugs. The major drawbacks with the therapeutic agents for mycobacterial and fungal infections are prolonged treatment regimen with a combination of drugs associated with significant toxicity and the emergence of multi-drug resistant bacteria and fungi causing morbidity and mortality in immunocompromised hosts. The necessity for effective therapy has stimulated research into the design and synthesis of novel compounds which can treat both mycobacterial and fungal infections. Design of compounds having good anti-tubercular activity is gaining much importance in the field of tuberculosis research due to the resurgence of antibiotic-resistant strains.
Mycobacterium tuberculosis enoyl-acyl carrier protein (ACP) reductase (InhA) has been validated as a promising target for antitubercular agents. InhA was identified as an NADH-dependent enoyl-ACP $(\mathrm{COA})$ reductase specific for long-chain enoyl thioesters and is a member of the Type II fatty acid biosynthesis system, which elongates acyl fatty acid precursors of mycolic acids which are components of the mycobacterial cell wall $[4,5]$.

Azoles exert antifungal activity through inhibition of cytochrome P450 14 $\alpha$-demethylase (CYP51), which is crucial in the process of biosynthesis of ergosterol by a mechanism in which the heterocyclic nitrogen atom (N-4 of 1,2,4-triazole) bind to the heme iron atom. Selective inhibition of CYP 51 would cause depletion of ergosterol and accumulation of lanosterol and other 14-methyl sterols resulting in the growth inhibition of fungal cells [6]. When a mercapto group attached to the heterocyclic rings enhance fungicidal activity. It has been reported that structural properties of triazoles, like moderate dipole character, hydrogen bonding capability, rigidity and stability under in vivo conditions are the main reasons for their superior pharmacological activities [7].

To date, the prevention of oxidative stress related diseases has been tentatively achieved by the development of antioxidant compounds that are able to scavenge reactive oxygen species and thus avoid radical-induced oxidation damage. Excessive free radical attack can damage DNA, proteins and lipids, resulting in diseases like cancer, neurological degeneration and arthritis, as well as the process of aging [8]. Therefore, considerable speculation has been directed towards the identification of antioxidants for use in preventive medicine.

In recent years, triazole derivatives have acquired conspicuous significance due to their wide spectrum of biological activities such as antibacterial [9], antifungal [10], antiviral [11], anti-inflammatory [12, 13], anthelmintic [14], antitubercular [15], antioxidant [16], antiplasmodial [17] and antileishmanial [18] activity. Nowadays, many triazole containing drugs are available in the market such as fluconazole, itraconazole, voriconazole, posoconazole anastrozole, estazolam, 
ribavirin, triazolam [19], etc. The search and evaluation of 1,2,4-triazole compounds and their derivatives with a specific pharmacological activity is a demanding task in the drug discovery process. This study aims to discover potentially active new 1, 2, 4-triazole derivatives through in silico drug designing as InhA and cyp 51 inhibitor. Also, we present an evaluation of the antioxidant effect of substituted triazole derivatives.

\section{MATERIALS AND METHODS}

\section{Lead optimization}

Lead optimization was done through in-silico Lipinski filter. Molinspiration server was used for this purpose [20]. The structure drawn in the JME molecule editor was subjected to analysis of Lipinski rule of five.

\section{Selection of target protein}

The 3D crystal structure of InhA receptor (entry code: 4U0J) [21] and CYP 51 receptor/fungal protein (entry code: 1EA1) [22] used for docking was recovered from the Brookhaven Protein Data Bank (http://www. rcsb. org/pdb/home). Reference compounds such as pyrazinamide and fluconazole are directly downloaded from DrugBank 2.5 database $[23,24]$, and they are potentially competitive inhibitor against target proteins.

\section{Active site prediction}

A prediction of the active site and ligand binding sites of 3D protein structure was done by using Computed Atlas of Surface Topography of proteins (CASTp) which is a web server that provides online services for locating, delineating and measuring geometric and topological properties of protein structures [25].

\section{Preparation of ligand files}

Ligand files for the molecular docking studies were prepared in Chem Draw Ultra software, Cambridge Soft Corporation, USA. Version-12.0, 1997-2010. It is a Chem Tech tool used for the drawing of ligand molecules. Compound structures were drawn in ChemDraw software and converted to pdb format (. pdb file) with the standard settings and further used for docking studies.

\section{Docking study}

Molecular docking studies performed with various targets like

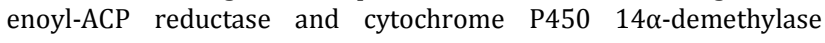

receptor with novel compounds were carried out by using AutoDock 4.2.1 and Auto Dock Tools (ADT) v 1.5.4 from the Scripps Research Institute. Firstly, all bound waters, ligands and cofactors were removed from the proteins. Then macromolecule was checked for polar hydrogen. Partial atomic Kollman charges were assigned, and then atomic solvation parameters were allotted. Torsion bonds of the inhibitors were selected and defined. Secondly, the threedimensional grid box was created by AutoGrid algorithm to evaluate the binding energy on the macromolecule coordinates. Grid maps representing intact ligand in the actual docking target site were calculated with AutoGrid. The three-dimensional grid box with a grid map of size $80 \times 80 \times 80$ of $\mathrm{x}, \mathrm{y}$ and $\mathrm{z}$-axis for different grid parameters with a spacing of $0.300 \mathrm{~A}{ }^{\circ}$ was created. Eventually, cubic grids encompassed the binding site where the intact ligand was embedded. Finally, resultant compounds were used to compute molecular stimulation parameters like Lamarckian genetic algorithm of population size 150, the mutation rate of 0.02 and crossover rate of 0.8 , these simulations were performed up to 2.5 million energy and the evaluations were maximum at 27000 generations. Each simulation was carried about 10 times which ultimately yielded 10 docked conformations. From this, the lowest energy conformations were regarded as the best binding conformations.

\section{Chemistry}

Chemicals used were purchased from Merck and Hi-Media, Mumbai, India. Vanillic acid (4-hydroxy-3-methoxy benzoic acid), carbondisulfide, potassium hydroxide, hydrazine hydrate, ethanol, and anhydrous ether was purchased from Merck. DMSO and aromatic amines (4-nitroaniline, 2-nitroaniline, 4-bromo aniline) were purchased from Hi-Media, India. All the chemicals were used without further purification. Melting points were determined in open capillary tube and were uncorrected. Purity of the synthesized compounds was routinely checked by thin layer chromatography on silica gel $\mathrm{G}$ with the solvent system-benzene: methanol (8:2) using iodine vapour for detection. IR spectra of the compounds were recorded using $\mathrm{KBr}$ pellets in the range of $4000-500 \mathrm{~cm}^{-1}$ on a Jasco FTIR spectrophotometer in Devaki Amma Memorial College of Pharmacy, Malappuram, India. ${ }^{1} \mathrm{H}$ and ${ }^{13} \mathrm{C}$ NMR spectra were recorded in $\mathrm{CDCl}_{3}$ on Bruker ultra shield DPX 400 spectrometer using tetramethylsilane as an internal standard (chemical shifts in $\delta$, ppm) and mass spectra on LC-MSD Trap-SL 2010 A-Shimadzu spectrometer at Interdisciplinary School of Indian System of Medicine (ISISM), SRM University, Chennai, India.

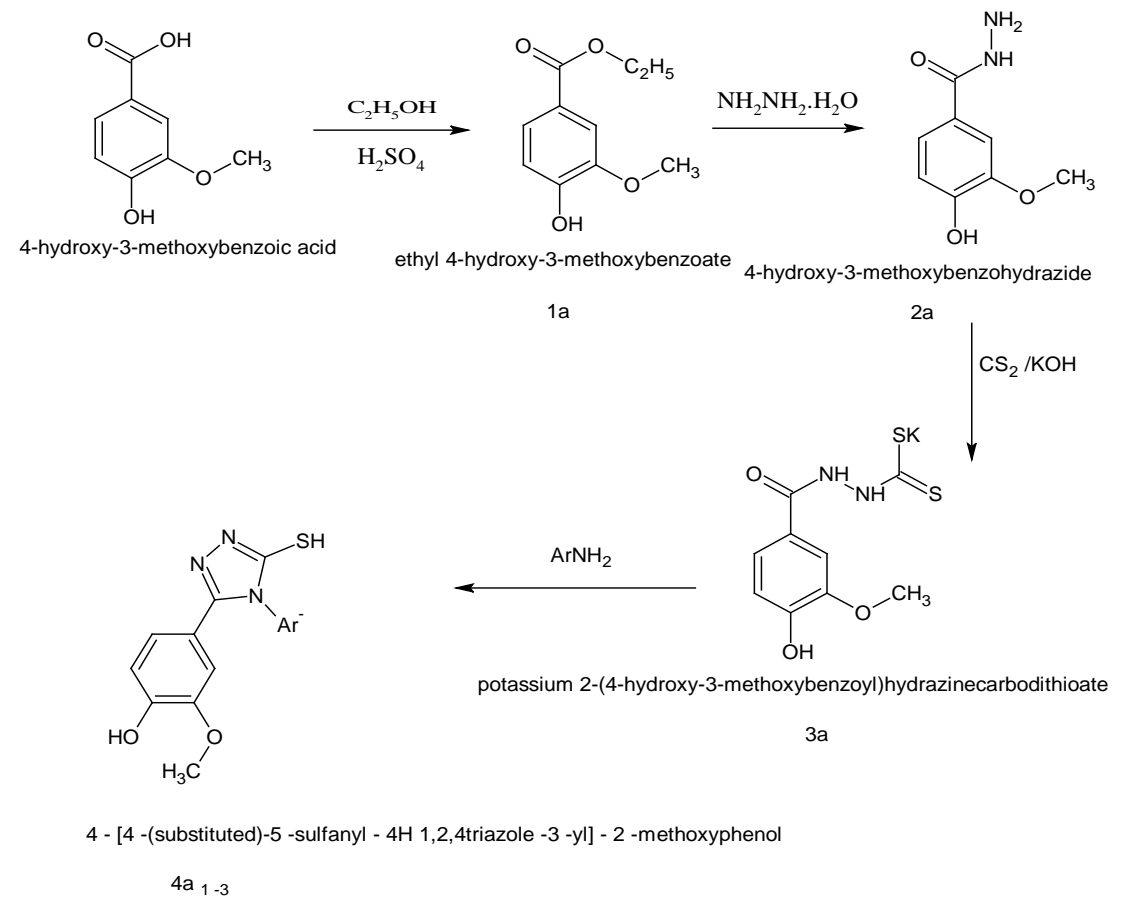

Fig. 1: Schematic presentation of synthesis of 4a1-4a3 


\section{Synthesis of ester (1a)}

A mixture of $0.01 \mathrm{~mol}$ substituted acid, $10 \mathrm{ml}$ of absolute ethanol and $2 \mathrm{ml}$ of concentrated sulphuric acid was refluxed for $4 \mathrm{~h}$. The product was recrystallized from ethanol.

\section{Synthesis of acid hydrazide (2a)}

A mixture of $0.01 \mathrm{~mol}$ ester and $0.2 \mathrm{~mol}$ hydrazine hydrate was refluxed in $50 \mathrm{ml}$ of $95 \%$ ethanol for $2 \mathrm{~h}$. The resultant mixture was acidified with concentrated hydrochloric acid. The solid mass thus separated out was filtered, dried and purified by recrystallization from ethanol.

\section{Synthesis of the potassium salt of dithiocarbazinate (3a)}

Potassium hydroxide $(0.01 \mathrm{~mol})$ was dissolved in absolute ethanol $(75 \mathrm{ml})$. To the above solution, acid hydrazide $(0.01 \mathrm{~mol})$ was added with stirring and cooling in ice. To this, carbon disulphide $(10 \mathrm{ml})$ was added in small portions. The reaction mixture was refluxed for 4-6 h. To the resulting solution, anhydrous ether $(250 \mathrm{ml})$ was added and precipitated potassium dithiocarbazinate was collected by filtration, washed with diethyl ether and dried. The dithiocarbamates were obtained in quantitative yield. As most of the potassium salt of dithiocarbazinates were moisture sensitive, they were employed directly for the preparation of aminomercapto triazoles without further purification.

\section{Synthesis of 5-mercapto-1, 2, 4-triazole derivatives $\left(4 a_{1}-4 a_{3}\right)$}

A suspension of potassium salt dithiocarbazinate $(0.01 \mathrm{~mol})$, hydrazine hydrate $(2 \mathrm{ml})$, water $(80 \mathrm{ml})$ and a primary aromatic amine $(0.01 \mathrm{~mol})$ was refluxed for $3 \mathrm{~h}$. The colour of the reaction mixture changed to green, hydrogen sulphide was evolved and a homogenous solution resulted. A white solid was precipitated by dilution with cold water. The product was filtered, washed with cold water and recrystallised from ethanol [26].

\section{Antitubercular activity}

Microplate Alamar Blue Assay (MABA) method was used for the study. Prior to the bioassay, a standard stock solution with the concentration of $32 \mu \mathrm{g} / \mathrm{ml}$ was prepared and stored to be used for the positive control. Control wells without tested derivatives and sterility controls were assayed simultaneously. Pyrazinamide was prepared from the stock solution just prior to inoculation time to the concentration of $5 \mu \mathrm{g} / \mathrm{ml}$ in the total volume of $200 \mu \mathrm{l}$. The growth inhibition result was explained by MABA using $1 \%$ resazurin. The reagent allows the detection of microbial growth in microtiter plates without the use of a spectrophotometer. The susceptibility test conducted by the MABA was using 96 well microtitre plates to evaluate the susceptibility of $\mathrm{H}_{37} \mathrm{Rv}$ MTB reference strain to the derivative. The inhibitory concentration of all derivative was evaluated with concentrations of $250 \mathrm{mg} / \mathrm{ml}, 500 \mathrm{mg} / \mathrm{ml}$ and 1000 $\mathrm{mg} / \mathrm{ml}$ in the total volume of $200 \mu \mathrm{l}$. The measured derivatives were mixed with the bacterial suspension and the diluent media (7H9) in the well. The alamar blue oxidation-reduction dye is a general indicator of cellular growth and/or viability; the blue, non- fluorescent, oxidized form becomes pink and fluorescent upon reduction. Growth was therefore determined by a visual color change. The derivatives were considered active (have inhibitory activity) for the well of the plate with unchanged color or the blue, non-fluorescent, oxidized form and if the color of the agent or resazurin is changed to pink (fluorescent) the derivative is inactive or the microorganism is considered resistant strain to the derivative [27].

\section{Antifungal activity}

All the synthesized compounds $(200 \mu \mathrm{g} / \mathrm{ml})$ in DMSO solvent were screened for in vitro antifungal activity by agar well diffusion method [26]. The activity was evaluated against pathogenic fungal strains such as Candida albicans (ATCC. 4563), Aspergillus niger (ATCC. 20611) using Sabouraud's dextrose agar medium. The fungal strains were procured from the Department of Microbiology, Devaki Amma Memoria College of Pharmacy. The results were compared with standard fluconazole $(25 \mu \mathrm{g} / \mathrm{ml})$. The plates were incubated for $48 \mathrm{~h}$ at $27{ }^{\circ} \mathrm{C}$ in an incubator. Plates were read only if the lawn of growth was confluent or nearly confluent. The diameter of the inhibition zone was measured to the nearest whole millimeter by holding the measuring device. The test was carried out in triplicate.

\section{Antioxidant activity}

In vitro antioxidant activity was carried out by 1,1-diphenyl-2picrylhydrazyl (DPPH) radical scavenging assay method [28]. Assay was carried out using UV spectrophotometer at $517 \mathrm{~nm}$. To $2 \mathrm{ml}$ solutions of synthesized compounds $(50,100,150$ and $200 \mu \mathrm{g} / \mathrm{ml}), 2$ $\mathrm{ml}$ DPPH solutions $(400 \mu \mathrm{mol})$ in ethanol were added into the test tube. The solution was incubated at $37{ }^{\circ} \mathrm{C}$ for $30 \mathrm{~min}$ and the absorbance of each solution was measured at $517 \mathrm{~nm}$ against a reagent blank solution. Ascorbic acid was used as reference antioxidant. Experimental values summarized for DPPH radical scavenging assays are expressed as the mean \pm standard error of mean (SEM). The percent free radical scavenging activity was calculated by the formula given by

Percentage scavenging

$$
=\frac{\text { Control absorbance }- \text { Test absorbance }}{\text { Control absorbance }} \times 100
$$

The experiment was done in triplicate. As opposed to increasing concentration of specimens decline of absorbance is an indication that destroyed DPPH radical. Antioxidant activity results are expressed as $\mathrm{IC}_{50}$ value $(\mu \mathrm{g} / \mathrm{ml})$ that reduces by half the effective concentration of DPPH radicals and was calculated by interpolation from the linear regression analysis.

\section{RESULTS AND DISCUSSION}

In silico molecular analysis of different triazole derivatives was done. All these compounds obeyed "Lipinski rule of five". These analogues were taken for computing molecular descriptors and which have the best docking score was taken for synthesis. The results are shown in table 1 .

Table 1: Analysis of lipinski rule of five

\begin{tabular}{lllllll}
\hline Compound code & Ar & Log p & H donor (nON) & $\begin{array}{l}\text { H acceptor } \\
\text { (nOHNH) }\end{array}$ & $\begin{array}{l}\text { No. of rotatable bonds } \\
\text { (nrotab) }\end{array}$ & Mol. Wt \\
of violation
\end{tabular}

Molecular modeling technique was used to explore, predict and understand the protein/enzyme interactions with designed 1, 2, 4-triazole library; and also to visualize the probable binding. Analogues were docked with various receptors using Autodock 4.2.1 and the binding energy obtained are shown in table 2 . Docking studies of targeted compounds with CYP51 protein showed good binding interactions and formed various hydrophobic interactions with active site residues. The ligand 4 a3 exhibited a docking score of 9.73, with the main hydrophobic interactions with the surrounding residues ALA191A, GLY192A, ILE194A and PR0193A, strongly contributed to the stabilization with 1EA1. The hydrogen bonding interaction of hydroxyl group protons of $4 \mathrm{a} 3$ were with the residues SER94A and LYS166A. 
Table 2: Docking result with proposed derivatives

\begin{tabular}{|c|c|c|c|c|c|c|}
\hline \multirow{2}{*}{$\begin{array}{l}\text { Compound } \\
\text { code }\end{array}$} & \multicolumn{3}{|l|}{ 1EA1 } & \multicolumn{3}{|l|}{ 4U0J } \\
\hline & $\begin{array}{l}\text { Binding energy (K. } \\
\text { Cal/Mol) }\end{array}$ & $\begin{array}{l}\text { Inhibition } \\
\text { constant }\end{array}$ & $\begin{array}{l}\text { No. Of H } \\
\text { bonds }\end{array}$ & $\begin{array}{l}\text { Binding energy (K. } \\
\text { Cal/Mol) }\end{array}$ & $\begin{array}{l}\text { Inhibition } \\
\text { constant }\end{array}$ & $\begin{array}{l}\text { No. Of H } \\
\text { bonds }\end{array}$ \\
\hline $4 a 1$ & -8.64 & $1.1 \mu \mathrm{M}$ & 4 & -8.47 & $1.05 \mu \mathrm{M}$ & 4 \\
\hline $4 a 2$ & -8.75 & $3.68 \mu \mathrm{M}$ & 3 & -8.39 & $4.06 \mu \mathrm{M}$ & 4 \\
\hline $4 a 3$ & -9.73 & $693.55 \mathrm{nM}$ & 4 & -8.55 & $1.34 \mu \mathrm{M}$ & 5 \\
\hline Fluconazole & -8.31 & $258.35 \mathrm{nM}$ & 3 & - & - & - \\
\hline Pyrazinamide & - & - & - & -8.1 & $2.96 \mu \mathrm{m}$ & 3 \\
\hline
\end{tabular}

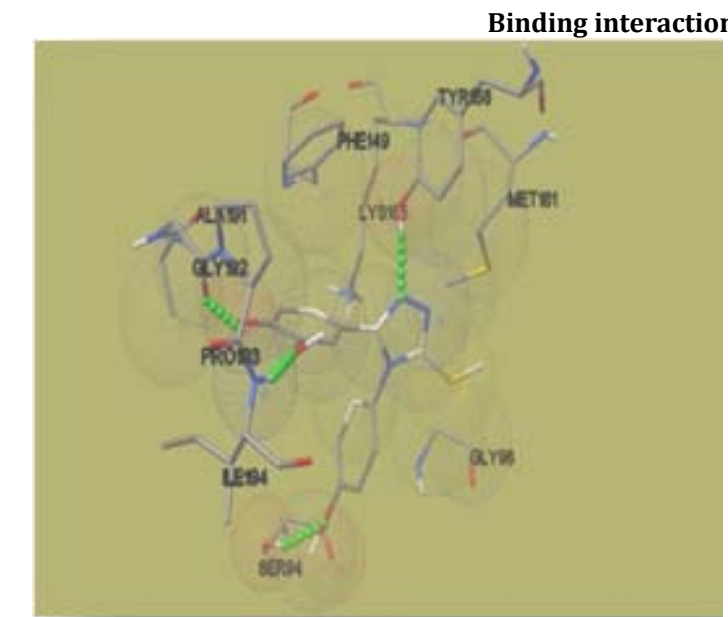

Fig. 2: Interaction of 1EA1 with 4a3

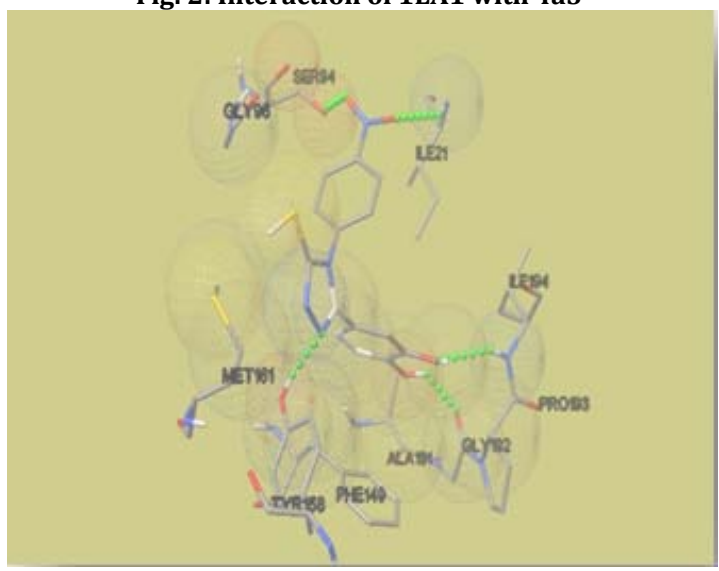

Fig. 4: Interaction of 4U0J with $4 \mathrm{a} 3$

Analogues designed by in-silico studies were selected for wet lab synthesis based on the good binding energy and availability. Three analogues were synthesized by a conventional method. The reaction sequence leading to the formation of titled compounds is shown on the scheme. First step in synthesis was esterification of carboxylic acids with alcohols which is a kind of nucleophilic acyl substitution. In the second step, an efficient and general process, involving preforming activated ester reacts with hydrazine, for the preparation of hydrazides. This process gives the desired hydrazides in excellent yield and purity under mild conditions

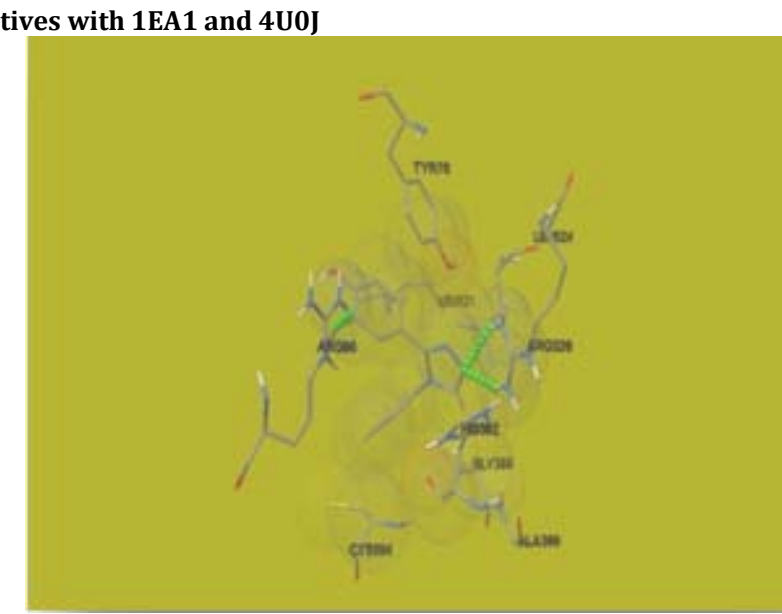

Fig. 3: Interaction of 1EA1 with 4a1

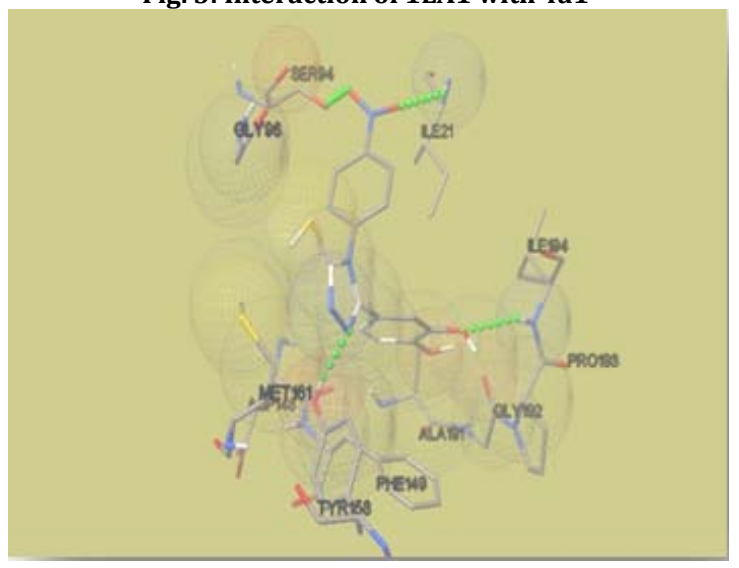

Fig. 5: Interaction of $4 \mathrm{U} 0 \mathrm{~J}$ with $4 \mathrm{a} 2$

[29]. The main synthetic route to dithiocarbamates is based on the interaction between the corresponding amine and CS2 in the presence of a strong base. It was found that upon decreasing of the protoning ability of the solvent, the rate of dithiocarbamate formation increases. Finally, potassium salt of dithio carbazinates was react with corresponding primary aromatic amines like 4bromo aniline, 4-nitroaniline and 2-nitroaniline, the ring cyclises to form 1,2,4-triazole derivatives (4a1-4a3). All the compounds were obtained in moderate to good yields. The physicochemical data of synthesized derivatives is given in table 3 .

Table 3: Physicochemical data of newly synthesized compounds

\begin{tabular}{llll}
\hline Compound & Physical appearance & Melting point in ${ }^{\circ} \mathbf{C}$ & R $_{\mathbf{f}}$ value \\
\hline 1a & Yellowish brown & 58 & 0.84 \\
2a & Yellowish orange & 198 & 0.87 \\
3a & Yellowish orange & 246 & 0.76 \\
$4 \mathrm{a} 1$ & Brown & 132 & 0.80 \\
$4 \mathrm{a} 2$ & Red & 64 & 84 \\
$4 \mathrm{a} 3$ & Pale yellow & 86 & 78 \\
\hline
\end{tabular}


The structures of all the newly synthesized compounds were confirmed by their IR, ${ }^{1} \mathrm{H}$ and ${ }^{13} \mathrm{C}$ NMR and mass spectral studies. All the newly synthesized compounds exhibited satisfactory spectral data consistent with their molecular structures.

4a1: Molecualr formula: $\mathrm{C}_{15} \mathrm{H}_{12} \mathrm{~N}_{4} \mathrm{O}_{4} \mathrm{~S}$, IR v (cm-1) (KBr) 3470 (NHstretching), 1700 ( $\mathrm{NO}_{2}$-stretching), 2610 (S-H-stretching), ${ }^{1} \mathrm{H}$ NMR $\left(\mathrm{CDCl}_{3}\right)(\mathrm{ppm}): \delta 5.01(\mathrm{~S}, 1 \mathrm{H}, \mathrm{OH}), 3.514(\mathrm{~S}, 1 \mathrm{H}, \mathrm{C}-\mathrm{SH}), 6.61-6.68(\mathrm{M}$, $\left.5 \mathrm{H}, \mathrm{C}_{6} \mathrm{H}_{5}\right), 2.507\left(\mathrm{~S}, 3 \mathrm{H}, \mathrm{CH}_{3}\right), 7.94-7.96\left(\mathrm{D}, 2 \mathrm{H}, \mathrm{CH}_{2}\right),{ }^{13} \mathrm{C} \mathrm{NMR}$ $\left(\mathrm{CDCl}_{3}\right) \mathrm{ppm}: \delta 156.08,136.23,126.79,112.85,56.58,40.41,40.25$, 40.17, 40.08, 39.91, 39.75, 39.58, 39.41, 18.92, MS m/z (\%):132.95, 176.95, 193.05, 239.10 (base peak), 344.34 (molecular ion peak).

4a2: Molecular formula: $\mathrm{C}_{15} \mathrm{H}_{12} \mathrm{~N}_{4} \mathrm{O}_{4} \mathrm{~S}$, IR v (cm-1) (KBr) 3470 (NHstretching), 1700 ( $\mathrm{NO}_{2}$-stretching), 2610 (S-H-stretching), ${ }^{1} \mathrm{H} \mathrm{NMR}$ $\left(\mathrm{CDCl}_{3}\right)(\mathrm{ppm}): \delta 2.51(\mathrm{~S}, 1 \mathrm{H}, \mathrm{C}-\mathrm{SH}), 3.42\left(\mathrm{~S}, 3 \mathrm{H}, \mathrm{CH}_{3}\right) 5.01(\mathrm{M}, 1 \mathrm{H}, \mathrm{C}-$ $\mathrm{OH})$, 6.6-7.95 (M, 7H, Aromatic $\mathrm{H}),{ }^{13} \mathrm{C} \mathrm{NMR}\left(\mathrm{CDCl}_{3}\right) \mathrm{ppm}: \delta 146.65$,
136.04, 130.83, 125.80, 119.62, 115.86, 40.47, 40.30, 40.14, 39.97, $39.80,39.64,39.47, \mathrm{MS} \mathrm{m} / \mathrm{z}(\%): 111.05,132.95,301.25$ (base peak), 344.34 (molecular ion peak).

4a3: Molecular formula: $\mathrm{C}_{15} \mathrm{H}_{12} \mathrm{BrN}_{3} \mathrm{O}_{2} \mathrm{~S}, \mathrm{IR} v\left(\mathrm{~cm}^{-1}\right)(\mathrm{KBr}) 2610$ (S$\mathrm{H}$-stretching), 510 (Ar-Br-stretching), 3517 (NH-stretching), ${ }^{1} \mathrm{HNMR}$ $\left(\mathrm{CDCl}_{3}\right)(\mathrm{ppm}): \delta 5.20(\mathrm{~S}, 1 \mathrm{H}, \mathrm{OH}), 6.56-7.4(\mathrm{D}, 7 \mathrm{H}$, Aromatic $\mathrm{H}), 3.53$ $\left(\mathrm{S}, 3 \mathrm{H}, \mathrm{CH}_{3}\right), 2.5(\mathrm{~S}, 1 \mathrm{H}, \mathrm{C}-\mathrm{SH}),{ }^{13} \mathrm{C} \mathrm{NMR}\left(\mathrm{CDCl}_{3}\right) \mathrm{ppm}: \delta 148.40$ 131.82, 116.37, 106.83, 56.69, 40.50, 40.34, 40.17, 40.00, 39.67, $39.50,19.06$, MS m/z (\%): 111.20, 206.10 (base peak), 378.24 (molecular ion peak).

\section{Antitubercular evaluation}

Antitubercular study was performed by MABA method using Mycobacterium tuberculosis $\mathrm{H}_{37} \mathrm{Rv}$ strain (ATCC 27294). In table 4 showed the antitubercular effect of synthesized derivatives.

Table 4: Antitubercular screening of synthesized derivatives

\begin{tabular}{ll}
\hline Test drugs & MIC in $\boldsymbol{\mu g} / \mathbf{m l}$ \\
\hline $4 \mathrm{a} 1$ & 25 \\
$4 \mathrm{a} 2$ & 25 \\
$4 \mathrm{a} 3$ & 12.5 \\
Pyrazinamide & 3.125 \\
\hline
\end{tabular}

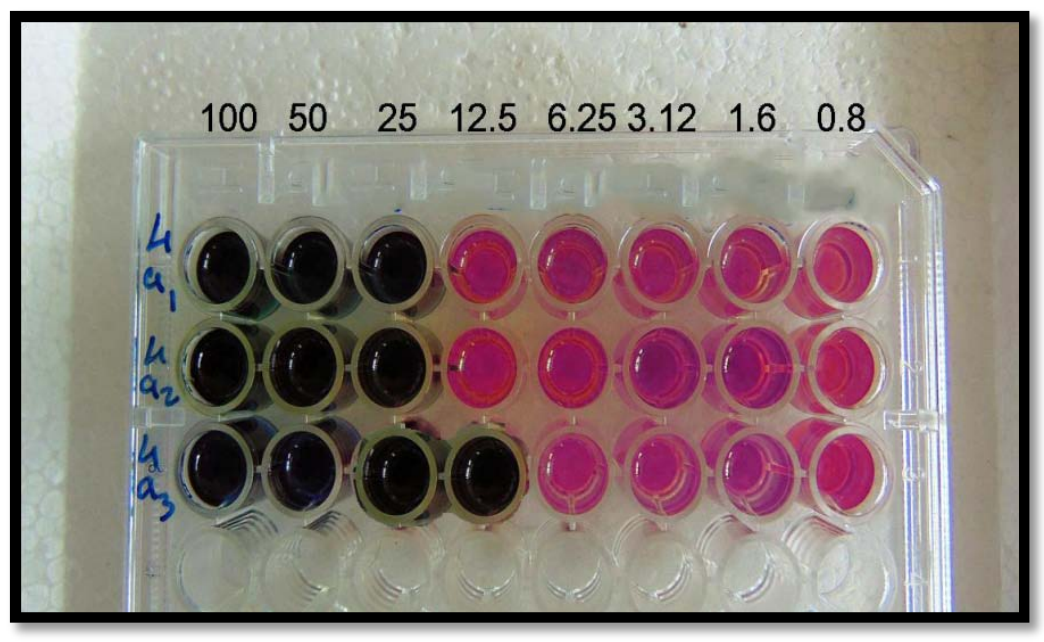

Fig. 6: Mycobacterial sensitivity to synthesized derivatives

Among the compounds evaluated 4-[4-(4-chlorophenyl)-5-sulfanyl4H-1,2,4-triazol-3-yl]-2-methoxyphenol (4a3) showed good binding affinity with Mycobacterial InhA, having minimum inhibitory concentration found to be $12.5 \mu \mathrm{g} / \mathrm{ml}$ compared with pyrazinamide as standard drug. The antitubercular data revealed that compounds having an electron withdrawing group like bromo attached to triazole nucleus may prove a template for antitubercular activity for further development.

\section{Antifungal evaluation}

The antifungal evaluation was done using 2 microorganisms i.e. Candida albicans and Aspergillus niger. Growth of inhibition of wells was determined using digital zone reader, and the datas are given in table 5. Azoles perform their antifungal action in two steps: inhibition of ergosterol synthesis, a major component of the fungal membrane and second step involves the blocking of P450dependent enzyme i.e., lanosterol 14- $\alpha$-demethylase (CYP 51). The 3D model of CYP 51 obtained on the basis MTCYP51 (M. Tuberclosis 14- $\alpha$-demethylase) showed that triazole ring coordinated to the heme iron of CYP51, a key step in antifungal activity of triazole. Lack of ergosterol and accumulation of 14- $\alpha$-demethylase disfunctionalize the fluidity of several enzyme located in the membrane which results in inhibition of fungal growth and replication of its DNA [30].

Table 5: Zone of inhibition of 4a1-4a3 in C. albicans and A. niger

\begin{tabular}{lll}
\hline Compound & \multicolumn{2}{c}{ Diameter of zone of inhibition (mm) in } \\
\cline { 2 - 3 } & C. albicans & A. niger \\
\hline 4a1 & $10.53 \pm 0.251$ & $8.25 \pm 0.031$ \\
4a2 & $11.86 \pm 0.305$ & $10.85 \pm 0.041$ \\
4a3 & $16.63 \pm 0.028$ & $15.69 \pm 0.015$ \\
Fluconazole $(25 \mu \mathrm{g} / \mathrm{ml})$ & $17.20 \pm 0.264$ & $17.86 \pm 0.638$ \\
DMSO & 0 & 0 \\
\hline
\end{tabular}

*Values are given mean \pm SD $(n=3)$ 


\section{Antioxidant evaluation}

Antioxidant evaluation was carried out by DPPH assay using ascorbic acid as a standard. The compounds 4a1-4a3 exhibited significant scavenging activity ranging from 40 to $88 \%$ and the data are expressed in mean \pm SEM in table 6 .
Many of them were shown to possess antioxidant properties and inhibit radicals by the effect of electron donating groups or supplying hydrogen atom. Based on the IC50 values of standard ascorbic acid and synthetic derivatives as showed in table 6, it is indicated that $4 \mathrm{a} 3$ shows better DPPH scavenging activity.

Table 6: Antioxidant evaluation of synthesized derivatives

\begin{tabular}{|c|c|c|c|}
\hline Compound & Concentration $(\mu \mathrm{g} / \mathrm{ml})$ & Percentage inhibition & $\mathrm{IC}_{50}(\mu \mathrm{g} / \mathrm{ml})$ \\
\hline \multirow[t]{4}{*}{ Ascorbic acid } & 12.5 & $18.23 \pm 0.483$ & 54.11 \\
\hline & 25 & $36.99 \pm 0.745$ & \\
\hline & 50 & $52.48 \pm 0.485$ & \\
\hline & 100 & $75.01 \pm 0.530$ & \\
\hline \multirow[t]{4}{*}{$4 \mathrm{a} 1$} & 50 & $40.05 \pm 0.028$ & 114.12 \\
\hline & 100 & $47.41 \pm 0.005$ & \\
\hline & 150 & $56.43 \pm 0.005$ & \\
\hline & 200 & $62.89 \pm 0.010$ & \\
\hline \multirow[t]{4}{*}{$4 \mathrm{a} 2$} & 50 & $45.37 \pm 0.0152$ & 122.46 \\
\hline & 100 & $47.29 \pm 0.0115$ & \\
\hline & 150 & $53.17 \pm 0.0208$ & \\
\hline & 200 & $75.01 \pm 0.530$ & \\
\hline \multirow[t]{4}{*}{$4 \mathrm{a} 3$} & 50 & $54.21 \pm 0.0208$ & 22.32 \\
\hline & 100 & $70.31 \pm 0.0057$ & \\
\hline & 150 & $80.44 \pm 0.0057$ & \\
\hline & 200 & $88.9 \pm 0.0100$ & \\
\hline
\end{tabular}

*Values are given mean \pm SEM $(n=3)$.

\section{CONCLUSION}

An attempt was made to explore the antitubercular potential of triazole scaffold in drug development. In this study, new mercapto1,2,4-triazole derivatives were designed and synthesized from potassium salt dithiocarbazinate and aromatic amines. The data obtained from ${ }^{1} \mathrm{H}$ NMR, ${ }^{13} \mathrm{C}$ NMR and mass spectra confirmed the proposed structures. The products were obtained in good yield. The synthesized compounds have been screened for in vitro antifungal activity and showed good to moderate antifungal activity. Results of in vitro antifungal, antitubercular activity, and molecular docking study revealed that the synthesized compounds have potential antifungal, antitubercular activity and can be further optimized and developed as a lead compound. 1, 2, 4-triazole derivative compounds were shown to have significant antioxidant properties as measured by DPPH scavenging assay.

\section{ACKNOWLEDGMENT}

The authors are thankful to SRM University for providing necessary facilities to carry out the NMR and mass spectral analysis and Leads Clinical Research, Bengaluru, India for providing antitubercular data.

\section{AUTHORS CONTRIBUTIONS}

All the authors have contributed equally.

\section{CONFLICT OF INTERESTS}

The authors declare that there is no conflict of interest.

\section{REFERENCES}

1. John Warren. Drug discovery: lessons from evolution. Br J Clin Pharmacol 2011;71:497-503.

2. Lengauer T, Rarey M. Computational methods for biomolecular docking. Curr Opin Struct Biol 1996;6:402-6.

3. Dolin, Gerald Mandell L, John Bennett E, Raphael Mandell. Douglas and bennett's principles and practice of infectious diseases. 7th ed. Philadelphia PA: Churchill Livingstone/Elsevier; 2010.

4. Ling LL, Xian J, Ali S, Geng B, Fan J, Mills DM, et al. Identification and characterization of inhibitors of bacterial enoyl-acyl carrier protein reductase. Antimicrob Agents Chemother 2004; 48:1541-7.

5. Oliveira JS, Vasconcelos IB, Moreira IS, Santos DS, Basso LA. Enoyl reductases as targets for the development of anti- tubercular and anti-malarial agents. Curr Drug Targets 2007;8:399-411.

6. Zhongjun Guan, Xiaoyun Chai, Shichong $\mathrm{Yu}$, Honggang $\mathrm{Hu}$, Yuanying Jiang, Qingguo Meng, et al. Synthesis, molecular docking and biological evaluation of novel triazole derivatives as antifungal agents. Chem Biol Drug Des 2010;76:496-504.

7. Stefania Felicia Barbuceanu, Diana Carolina Ilies, Gabriel Saramet, Valentina Uivarosi, Constantin Draghici, Valeria Radulescu. Synthesis and antioxidant activity evaluation of new compounds from hydrazinecarbothioamide and 1, 2, 4-triazole class containing diaryl sulfone and 2,4-difluoro-phenyl moieties. Int J Mol Sci 2014;15:10908-25.

8. Ahmet Cetin, Ibrahim Halil Gecibesler. Evaluation as antioxidant agents of 1,2,4-triazole derivatives: essential functional group effects. J Appl Pharm Sci 2015;5:120-6.

9. Nareshvarma Seelam, Shrivastava SP, Prasanthi S, Supriya Gupta. Synthesis and in vitro study of some fused 1, 2, 4triazole derivatives as antimycobacterial agents. J Saudi Chem Soc 2016;20:411-8.

10. Sheng CQ, Zhang WN, Ji HT, Zhang M, Song YL, Xu H, et al. Structure-based optimization of azole antifungal agents by CoMFA, CoMSIA and molecular docking. J Med Chem 2006;49:2512-25.

11. Wang Z, Wu B, Kuhen KL, Bursulaya B, Nguyen TN, Nguyen DG, et al. Synthesis and biological evaluations of sulfanyl triazoles as novel HIV-1 non-nucleoside reverse transcriptase inhibitors. Bioorg Med Chem Lett 2006;16:4174-7.

12. Navidpour L, Shafaroodi H, Abdi K, Amini M, Ghahremani MH, Dehpour AR, et al. Design, synthesis, and biological evaluation of substituted 3-alkylthio-4,5-diaryl-4H-1, 2, 4-triazoles as selective COX-2 inhibitors. Bioorg Med Chem 2006;14:250717.

13. Prabhu Jalihal C, Vaibhav Rajoriya, Varsha Kashaw. Design, synthesis, and evaluation of new derivative of 1,2,4-triazoles for antimicrobial and anti-inflammatory activity. Int J Curr Pharm Res 2018;10:29-35.

14. Jeetendra Kumar Gupta, Pradeep Mishra. Antimicrobial and anthelmintic activities of some newly synthesized triazoles. Asian J Pharm Clin Res 2017;10:139-45.

15. Yasodakrishna Sajja, Sowmya Vanguru, Hanmanth Reddy Vulupala, Rajashaker Bantu, Perumal Yogeswari, Dharmarajan Sriram, et al. Design, synthesis and in vitro anti-tuberculosis activity of benzo [6, 7] cyclohepta [1,2-b]pyridine-1,2,3-triazole derivatives. Bioorg Med Chem Lett 2017;27:5119-21. 
16. Arif Mermer, Neslihan Demirbas, Yakup Sirin, Harun Uslu, Zeynep Ozdemir, Ahmet Demirbas. Conventional and microwave prompted synthesis, antioxidant, anticholinesterase activity screening and molecular docking studies of new quinolone triazole hybrids. Bioorg Chem 2018;78:236-48.

17. Bakunov SA, Bakunova SM, Wenzler T, Ghebru M, Werbovetz KA, Brun R. Synthesis and antiprotozoal activity of cationic 1,4diphenyl-1H-1,2,3-triazoles. J Med Chem 2010;53:254-72.

18. Guimaraes TT, Pinto FR, Lanza JS, Melo MN, Monte-Neto RL, Melo IMM. Potent naphthoquinones against antimony sensitive and resistant Leishmania parasites: synthesis of novel $\alpha$-and nor- $\alpha$-lapachone based 1,2,3-triazoles by copper catalyzed azide-alkyne cycloaddition. Eur J Med Chem 2013;63:523-30.

19. Zhou $\mathrm{CH}$, Wang Y. Recent researches in triazole compounds as medicinal drugs. Curr Med Chem 2012;19:239-80.

20. Rucha Wadapurkar M, Shilpa MD, Anil Kumar Katti S, Sulochana MB. In silico drug design for Staphylococcus aureus and development of host-pathogen interaction network. Informatics Medicine Unlocked 2018;10:58-70.

21. He X, Alian A, Stroud RM, Ortiz de Montellano PR. Pyrrolidine carboxamides as a novel class of inhibitors of enoyl acyl carrier protein reductase from Mycobacterium tuberculosis. J Med Chem 2006;19:6308-23.

22. Podust LM, Poulos TL, Waterman MR. Crystal structure of cytochrome P450 14alpha-sterol demethylase (CYP51) from Mycobacterium tuberculosis in complex with azole inhibitors. Proc Natl Acad Sci USA 2001;13:3068-73.

23. Schroeder EK, Basso LA, Santos DS, de Souza ON. Molecular dynamics simulation studies of the wild-type, 121V and I16T mutants of isoniazid-resistant Mycobacterium tuberculosis enoyl reductase (InhA) in complex with NADH: toward the understanding of NADH-InhA different affinities. Biophys J 2005;89:876-84.

24. Bellamine A, Lepesheva GI, Waterman MR. Fluconazole binding and sterol demethylation in three CYP 51 isoforms indicate defferences in active site topology. J Lipid Res 2004;45:2000-7.

25. Tian W, Chen C, Lei X, Zhao J, Liang J. CASTp 3.0: computed atlas of surface topography of proteins. Nucleic Acids Res 2018;2:W363-7.

26. Shashikanth Pattan, Priyanka Gadhave, Vishal Tambe. Synthesis and evaluation of some novel 1,2,4-triazole derivatives for antimicrobial, antitubercular and antiinflammatory activities. Indian J Chem 2012;51B:297-301.

27. Holla BS, Mahalinga M, Karthikeyan MS, Akberali PM, Shetty NS. Synthesis of some novel pyrazolo[3,4-d]pyrimidine derivatives as potential antimicrobial agents. Bioorg Med Chem 2006;14:2040-7.

28. Sethupandian Geetha, Kokkaiah Irulandi, Palanichamy Mehalingam. Evaluation of antioxidant and free radical scavenging activities of different solvent extracts of leaves of piper umbellatum. Asian J Pharm Clin Res 2017;10:274-6.

29. Xini Zhang, Michael Breslav, Jeffrey Grimm, Kailin Guan. A new procedure for preparation of carboxylic acid hydrazides. J Org Chem 2002;67:9471-4.

30. Hitchcock CA, Dickinson K, Brown SB, Evans EGV, Adams DJ. Interaction of azole antifungal antibiotics with cytochrome $\mathrm{P}$ 450-dependent 14 alpha-sterol demethylase purified from Candida albicans. Biochem J 1990;266:475-80. 